\title{
Academic-Service Partnerships, Research, and the South African Dental Academic
}

\author{
Elly S. Grossman, Ph.D.; Sudeshni Naidoo, Ph.D.
}

Abstract: In South Africa, academic dentistry is managed through joint agreements between the South African Department of Health $(\mathrm{DoH})$ and each university, in a type of academic-service partnership. For this study, dental faculty members were surveyed to ascertain staff attitudes towards academic research in dental schools and to find out whether the joint arrangement impinges upon research activities. A survey was distributed to 200 members of the South African division of the International Association for Dental Research (SA IADR) and the academic staff of the four South African dental schools. One hundred and five responses were obtained for a response rate of 53 percent; most of the respondents were lecturers (26 percent), specialists (17 percent), heads of department (17 percent), or senior lecturers (13 percent). The majority were employed by the DoH ( 77 percent) and were members of the SA IADR (51 percent). Most reported feeling that research is an important issue in their school (83 percent) and perceived general research output had declined (59 percent). While 79 percent said they were concerned about the decline, many (71 percent) felt there was little they could do about it. The respondents mentioned the following as reasons for the decline: lackluster approach of DoH structures, weak university support, poor research equipment and facilities, inadequate funding, emphasis on service delivery, undergraduate teaching loads, onerous working conditions, and lack of vision, leadership, and governance by senior management. Faculty members' twin obligations of service delivery (required by the DoH) and teaching (required by their institutions) have severely impacted South African academic dental research.

Dr. Grossman is Head, Division of Experimental Odontology, School of Oral Health Sciences, Faculty of Health Sciences, University of the Witwatersrand, South Africa; and Dr. Naidoo is Senior Professor, Principal Specialist, and Deputy Dean for Postgraduate Studies and Research, Faculty of Dentistry, University of the Western Cape, South Africa. Direct correspondence and requests for reprints to Dr. Elly Grossman, P.O. Box 14, Cannon Rocks, South Africa; 27-46-654-0480; grossmane@gmail.com.

Keywords: dental education, dental research, dental schools, faculty development, research incentives, South Africa

Submitted for publication 7/27/11; accepted 11/27/11

I ncreasingly, South African universities have become more reliant on government subsidies to fund their operating costs. Subsidies are based on the output of accredited original research publications and number of graduates. ${ }^{1}$ This focus on original research and higher degree output is an incentive to encourage academic institutions to develop a stronger research culture and increase research production, thereby propelling South Africa into a knowledgebased economy. ${ }^{2}$ Unfortunately, this push towards enhanced research productivity has come at a time when South African dental research is experiencing a decrease in research output. One study ${ }^{3}$ reported that South African ISI-rated publications in the field of dentistry/oral surgery and medicine experienced a 14 percent decline between 1981-85 and 2000-04. This trend was confirmed in a fifty-year case study that examined the South African dental research entity publication record ${ }^{4}$ and local dental conference presentations. ${ }^{5,6}$

Some background is necessary to contextualize current South African dental research and academic conditions and clarify our academic-service partnership circumstances. In the late 1970s, the Department of Health $(\mathrm{DoH})$ nationalized health care facilities under its control, with patient care and service delivery as priorities. In doing so, all university-paid, academic clinical staff were shifted to become government employees, with the DoH's conditions of service. Under such conditions, clinical qualifications - not research qualifications such as a $\mathrm{Ph}$.D. or research experience as measured by research journal publications - became prerequisites for appointment and promotion. These staff members are regarded as having joint appointments with the $\mathrm{DoH}$ and the university, where in the latter case research acumen is highly desirable and in this setting plays an important role in career advancement, as elsewhere. ${ }^{7}$ Any potential clinical researcher entering one of the four South African academic dental institutions desirous of doing research is quickly confronted with the realities of joint appointment commitments. Health care and service delivery are prioritized by the DoH employer who regulates the dental hospitals attached to the dental school. In this environment, the potential clinical researcher ensures all clinical requirements are met and supplies are stocked and in order and oversees patient flow, selection, management, and record-keeping, in addition to performing other duties. 
In the university environment, the core faculty business of undergraduate teaching is paramount, with attendant tasks such as curriculum development, examinations, and clinical supervision, as well as administrative tasks that gobble up the potential clinical researcher's time. Should research be published or a Ph.D. completed, kudos in the form of a financial research incentive from the Department of Higher Education and Training (DHET) are awarded. However, the awards are channeled through the university, and such monies are often retained by the institution so that no tangible acknowledgment comes from the employer (DoH) to the researcher. Consequently, the clinical and public health disciplines produce less than 10 percent of the country's total Ph.D.'s. ${ }^{8}$ Those clinicians with higher degrees such as a master's or doctorate are predominantly in academia where they have found a haven to pursue their research interests. ${ }^{9}, 10$

A further contributing factor to the decline in dental research has been the disconnect between the Colleges of Medicine of South Africa (CMSA) and the academic requirements for clinical specialist training, which went into effect in 1974. The academic route requires completion of an appropriate master's degree (for example, at the University of the Witwatersrand, a Master of Dentistry [M.Dent.]), which entails academic coursework, examinations, and a research component. The CMSA route, by contrast, permits registrable qualification as a clinical specialist upon completion of the identical academic course and examination requirements, but without the time-consuming research component. Consequently, a sizable proportion of trainees eager to enter private clinical practice take the simpler CMSA route and abandon the research component of the M.Dent., to the detriment of future research skills capacity and progression to a doctoral degree. These two factors (an unsupportive research environment, exacerbated by M.Dent. dropout rates ${ }^{9}$ ) have contributed to the thirty-year decline in oral health sciences research.

Ironically, the DoH has long been aware of the consequences of undercapacity in this area. A DoH White Paper in 1997 noted that "a culture of research and technology is essential for the future development of the country." 11 Ten years later, the DoH called on "universities [to] produce enough researchers, scientists, and specialists to contribute significantly to health science education and training." 12

The situation is about to change-with pressure coming from broad government recognition that future economic growth relies on new knowledge, in- novation, and technologies that require highly skilled labor in the form of Ph.D.'s, ${ }^{8}$ who are the life blood of research and innovation. In addition, as of 2011, the Health Professionals Council of South Africa (HPCSA) now requires the completion of a research component for registration as a clinical specialist in South Africa. Furthermore, the HPCSA has called for protected study time (20 percent, or eight hours per week) for registrars from their clinical duties. It acknowledges that registrars work unacceptably long hours, which impacts negatively on research and study. ${ }^{13}$ Cooperation has been forthcoming from the provincial Gauteng Department of Health (GDH) in the form of a recent memorandum of understanding ${ }^{14}$ between the GDH and the regional Universities of Limpopo, Pretoria, and the Witwatersrand that clarifies responsibilities to provincial and academic departments. (Gauteng Province is the most populous province in South Africa; it contains the cities of Johannesburg and Pretoria and is considered the economic hub of the country.) Surprisingly, oral health care was not mentioned specifically in this memorandum. Nonetheless, such initiatives have motivated an increased level of prospective master's degree candidates who are now required to complete a research component to obtain their specialist degree. Due to the national imperative to produce more doctoral graduates and to produce scientific knowledge for economic, social, and ecological development, the South African dental community will potentially be able to regain the eminent position in global dentistry it held prior to the 1980s.

Meanwhile, the question remains: how can dental schools jumpstart academic research to create new knowledge and nurture the next generation of clinical researchers when they have lost a research culture and accumulated a thirty-year research capacity backlog at the master's level? To begin to address these issues, data are required to fully understand academic dentists' attitudes and experience regarding research in their schools. Second, we need to know how faculty members juggle their research activity, if any, with their teaching and commitment to students and patients. The information gathered about barriers and bridges to research in the academic-service partnership paradigm can be used for future modeling to restore South African dental research. Hopefully, our experience can also benefit others who are considering introducing academic-service partnerships into their own dental schools.

For these reasons, a survey was conducted to determine the attitudes towards research of members 
of the South African division of the International Association for Dental Research (SA IADR) and academic staff members of the School of Dentistry, University of Limpopo; School of Dentistry, University of Pretoria; School of Oral Health Science, University of the Witwatersrand (all within the Gauteng Province); and Faculty of Dentistry, University of the Western Cape in the Western Cape Province. This exploratory study of faculty members' experiences in and attitudes towards research was designed to determine how their dual responsibilities of service delivery (required by the DoH) and teaching excellence (required by the universities) have affected their ability to conduct research.

\section{Methods and Materials}

Approval for the study was obtained from the University of the Witwatersrand Human Research Ethics Committee (Medical) for Clearance of Research, clearance number M070103. A survey consisting of twenty-eight open- and closed-ended questions was distributed in 2007 to a total sample of 200 SA IADR members and the academic staff members of all four South African dental schools via the SA IADR e-mail list. Hard copies of the survey were also distributed to staff members with the permission of each dean/head of the school. We were initially concerned that using the SA IADR list might introduce a sample bias to our study. In reality, the vast majority of SA IADR members are working in academic dentistry, so we decided that this route to study participants would not unduly bias our results. In 2007, the SA IADR membership stood at 119: 103 individuals were regular members, thirteen were retired, and three were student members.

An introductory letter was sent with an invitation to participate; this initial correspondence was followed by one reminder. The questions were divided into four broad areas: demographics of each respondent; current research activity, including research supervision; attitudes towards academic research; and factors inhibiting/promoting research activity within the respondents' dental schools. Open-ended questions followed thirteen of the closed-ended questions, asking for elaboration on the responses. A final question invited respondents to raise any other issues affecting their academic research experience not covered by the survey. This last question was included so that unanticipated themes could emerge from the respondents.
Data from the closed-ended questions were entered into an Excel spreadsheet and descriptively analyzed using StatsDirect (Cheshire, UK). Because this was an exploratory study, it was decided that the analysis of the open-ended questions should be guided in the first instance by the responses of the participants. Hence, the responses were coded and used to generate themes.

\section{Results}

A response rate of 53 percent was achieved, with 105 completed questionnaires returned from a potential sample of 200. Anonymity of responses prevented a detailed breakdown by dental school. In many instances, a respondent raised several diverse issues, not always related to the topic at hand. For this reason, percentages in the results do not always add up to 100 percent (Table 1). Transcribed comments probing research issues totaled fifty typed pages. For purposes of authenticity and to capture the richness of staff experiences, detailed descriptions from the data are included here.

The respondents came from all academic levels: lecturers ( 26 percent), specialists (17 percent), heads of department (17 percent), senior lecturers (13 percent), and registrars/junior lecturers (13 percent). Deans or heads of school made up 2 percent of responses, with other (13 percent) accounting for retirees, those with dual appointments, and oral hygienists. (Staffing hierarchy from lower to higher is as follows: junior lecturer, lecturer, senior lecturer, head of department. A registrar is a trainee specialist usually ranked at junior lecturer level, and a specialist or clinical specialist will normally be appointed at lecturer level or higher, depending on experience.) Most of the respondents were employed by the DoH (77 percent) and were members of the SA IADR (51 percent). Most (70 percent) had a master's degree and/or specialist qualification, with 22 percent having more than one higher qualification, which could be another master's, a Ph.D., or other higher degree. In the latter case, it was gratifying to note that sixteen respondents (15 percent) had a Ph.D., D.Sc., or M.D.S. However, of those sixteen, only nine had a clinical background and were still active staff members. The other seven were life scientists or retired clinicians. Twelve percent had a basic dental degree as their only qualification. 
Table 1. Responses to selected closed-ended questions on survey

Question

1. What position do you hold in the school?

2. Are you an SA IADR member?

3. Who pays your salary?

5. Is research an important issue in your school?

6. Has research output improved/declined in your dental school over the past years?

10. What do you think are the main reasons for your not doing research? Tick as many as you wish.

11. Should research be included as a compulsory undergraduate course?

12. Should research be included as a compulsory postgraduate course, no matter the degree?

13. Are you research-active?

17. What support do you get in terms of encouraging research?

18. Are you allocated research incentive monies generated by your own publications?

20. Do you mentor or supervise under- or postgraduate students in research?

24. Are you concerned about the low research output of your school?
Response

Junior lecturer $7 \%$; registrar $6 \%$; lecturer $26 \%$; senior lecturer $13 \%$; specialist lecturer $17 \%$; head of department $17 \%$; head of school/dean of faculty $2 \%$; other $13 \%$

Yes $51 \%$; no $48 \%$; unknown $1 \%$

University 25\%; provincial health department $77 \%$; other $7 \%$

Yes $83 \%$; no $12 \%$; uncertain/not answered 5\%

Improved 16\%; declined 59\%; not sure 11\%; uncertain/not answered $14 \%$

Time 62\%; administration 50\%; teaching 43\%; disinterest

$11 \%$; others better qualified should do research $9 \%$;

obligations to school are best fulfilled by teaching $19 \%$;

other (please elaborate) $49 \%$

Yes 76\%; no 19\%; uncertain/not answered 5\%

Yes 90\%; no 8\%; uncertain/not answered 2\%

Yes 70\%; no 25\%; uncertain/not answered 5\%

Dedicated research time $17 \%$; relief from teaching duties

$2 \%$; other $58 \%$; uncertain/not answered $23 \%$

All 4\%; some 41\%; none 38\%; uncertain/not answered $17 \%$

Yes $60 \%$; no 37\%; uncertain/not answered 3\%

Yes $79 \%$; no $10 \%$; uncertain/not answered $11 \%$

Note: Responses to questions 1 and 3 total more than 100 percent because of dual positions or salaries and joint appointments.

\section{Research Activity and Attitudes}

Asked about their current research activity, 70 percent of the respondents reported that they were "research-active." This response was further explored in four areas of possible endeavor: publications; conversance with current research literature; attendance or presentation at research forum or conference; and research supervision. Thirty-eight percent of the respondents said they had published a paper in the last year and 13 percent had in the past two years; 30 percent said they had never published at all. The remainder reported a paper last published between three and twenty-two years previously. Most (89 percent) of the respondents said they had read a journal article within the last year, and 78 percent reported attending an oral research presentation or making such a presentation within the past year. Many (60 percent) reported having supervised under- or postgraduate research, but only 32 percent said they had a postgraduate student who graduated in the past year and 56 percent had never supervised a postgraduate completing the degree. In the last case, it was not clear whether the respondent had never supervised a postgraduate as opposed to an undergraduate or whether his or her postgraduates had dropped out without completing the degree.

The vast majority ( 83 percent) of the respondents reported feeling that research was an important issue in their dental schools and perceived research output to have declined in recent years (59 percent). While 79 percent said they were concerned about the low research output of their dental schools, most (71 percent) of the respondents indicated there was little 
they could do about it. One wrote, "I have tried just about everything. I have literally given them projects 'on a plate,' yet they still don't respond or make any effort to progress." A small percentage (16 percent) of the respondents were of the opinion that school research output had actually improved. Comments included these: "only 1 or 2 depts-because of leadership in dept (+ interest by leader)"; "new staff; young members eager to research"; and "marginal research output improvement possibly due to the merging of the faculties." Nineteen percent of the respondents reported feeling their commitments to the school were best served doing clinical teaching: "registrar commitments (clinical and primaries)" was one's comment. Eleven percent reported being disinterested in research: one wrote, "My passion is teaching and not research." Nine percent said they felt that others who were better qualified should do research: one comment was "lack of skills to undertake research." Another respondent acknowledged that workplace realities dictated the type of research that could be done: "As you are aware, the type of research many of us do is nothing new or earthshattering —we shear, bond, microleak, etc. because it is quick, cheap, and easy."

\section{Factors Inhibiting or Promoting Research}

The respondents selected the following as personal factors hindering research: lack of time (62 percent), which was due mainly to administrative duties (50 percent), heavy teaching loads (43 percent), and service delivery ( 29 percent). Time factors were said to be exacerbated by such factors as "the department is understaffed," "tremendous clinical workload," and "professional lives ... ruled by the timetables." Staffing issues received much attention from respondents at all levels, be it academic, administrative, or support staff. "I would like to be involved in research but am the only full-time specialist in our department supervising six postgraduate students, clinical work, and undergraduate teaching," wrote one respondent. Another noted the "lack of supporting staff in clinics as well as administrative staff. . . a lot of time is wasted by professional staff in obtaining instruments, files, properly functioning chairs, and simple tasks that dental assistants could perform." Interpersonal tensions within the respondents' dental schools, lack of vision, and weak leadership by senior management were also mentioned as being partly to blame for poor research output. Comments included these: "head of school for whom academic activities are less important than bureaucratic activities"; "lack of strategic planning and vision within the department, as well as within the faculty as a whole"; and, tellingly, "Stop wasting time on rubbish and check on whether people are working. Our lecturers and superiors are very lazy."

More than half of the respondents complained that they received no support or encouragement to carry out research and said that self-motivation (29 percent) was their primary driver: "You have to make your own time and have a love for it (mostly after hours)," wrote one. Seventeen percent of the respondents reported being granted dedicated research time ("Since February I have been given two days a week," commented one); but only 2 percent said they obtained relief from teaching duties. The DHET research incentive subsidies also received comment. Some (41 percent) of the respondents said they were allocated part of the subsidy monies for research spending as they wished, 38 percent said they got no monies at all, and a lucky 4 percent reported receiving the entire amount. However, there was a general air of perplexity about research incentives: one wrote, "The university is very mysterious about handling these research incentive monies. I have never spent any of it." The lack of/need for support was referred to by the respondents time and time again, whether regarding funding (27 percent), a dedicated research unit (35 percent), technical help, instrumentation, equipment, training, mentoring, or other needs.

Seventy-six percent of the respondents said they felt research in dental schools was promoted by the compulsory research component currently included at the undergraduate level: "Students get a 'taste' for research and in many cases would continue with their research," commented one. Ninety percent of the respondents reported the same feeling about research at the postgraduate level, no matter the degree. One wrote, "If postgraduates are consumers of available research evidence, they also have an obligation to contribute to the body of knowledge." However, the high dropout rate of registrars was mentioned more than once: "Please penalize postgraduate students who do not complete their research components - penalty should be monetary," pleaded one respondent.

The final question inviting further comments not covered by the survey generated a torrent of comments. A particularly sore point was lack of research-based promotion by the DoH: "no promotions, incentives - nothing," wrote one. "Sometimes I wish 
I had stayed in private practice where I could have controlled my own destiny!" Incentives to stimulate research were also alluded to time and again, in such comments as these: "Full-time employed academics receive no more tax relief for attending congresses," and "Maybe a little money would help as an encouragement." Money was not the only form mentioned for incentives to take: one respondent remarked, "Encouragement and vision build incentive," and another wrote, "Could do with online subs with especially the dental education journals - library funding?" A third suggested "acknowledgment by the university authorities."

Abandonment by the university formed one of the many themes within this section. One respondent wrote, "Recently the deputy vice chancellor (academic) addressed the school, and for the first time in several years, it was as if the university realized we were part of its structure and staffing." However, heavy-handedness on the part of the DoH also came in for criticism. One respondent commented, "We are paid by the Dept. of Health, who expects far too much 'service rendering' from our staff. We have become 'state dentists' instead of academics"; another wrote, "Government wants staff to treat patients - that's it - end of story." Many respondents expressed divided and conflicting loyalties in which immediate responsibilities and their consciences determined their workflow pattern. Comments included the following: "Service rendering (patient care) takes priority"; "If you have a time problem, you must decide which is the most important: student training, which is your first obligation, or research. I would love to do both"; and "All preparation for lectures and blocks and marking has to be done after hours."

Finally, one respondent observed, "It seems that it's always the same people who are publishing/doing research, etc. I'm not quite sure why." The answer may lie in the following comments by two other respondents. One wrote, "Personally, I am involved in research, enjoying it thoroughly. Yes, teaching is vital and so is our input with students, but this is one aspect I personally treasure, am excited about, and I believe I should remain in this academic environment." The other pointed to receiving "a major thrill from publications."

\section{Discussion}

Our extensive online searches found no similar studies investigating research capacity in a state oral health care training facility such as ours. Therefore, our study can be regarded as a unique insight into the long-term outcome of a national academic-service partnership and the impact of this partnership on research and research training. In response to our first research question - what are staff experiences of and attitudes towards research? - the answer is that the vast majority of staff realize the value of research and are perturbed by its decline. Unfortunately, most feel that reversing the trend is beyond their personal or the dental school's control, citing a plethora of barriers preventing any change for the better. These include the lackluster approach of the $\mathrm{DoH}$, weak university support, poor research equipment and facilities, inadequate funding, limited mentors, interpersonal tensions within dental schools, emphasis on service delivery, onerous working conditions, and lack of vision and leadership by senior management - most of which have been cited in other studies. ${ }^{15-23}$

As to the second research question-how does the effect of dual responsibilities towards the DoH and universities impact the abilities of staff members to do research? - the short answer is that it makes conducting research difficult. There are pockets of sustained research present, often at the departmental level, where a research ethos is maintained. This situation accounts for how about half of those surveyed had managed to publish a scientific paper within the past two years. In some instances, however, there was rueful acknowledgment that the level of research is "quick, cheap, and easy," as one respondent said. Such an admission dovetails with a previous observation $^{15}$ that faculty members in emerging countries do not do cutting-edge research because of insufficient funds. Furthermore, it becomes difficult for faculty members to keep current with research advances, which denies students a "high-quality research experience" 15 in the dental education setting. This is true in our case in South Africa and has further reduced our potential for research training.

The promotion of research by support or reward is further derailed by the joint appointments system. Our respondents said they had frequently requested support in the form of technical or science-trained staff, yet the DoH has been reluctant to fund such posts as it would not contribute directly towards its mission of patient care. Likewise, universities find it difficult to commit to a permanent position when the employee will be working in a government environment, outside university control. Freer ${ }^{23}$ has drawn attention to a comparable anomaly occurring in Australia. Other studies have mentioned that rewards in 
the form of salary bonuses or merit increases stimulate research output, ${ }^{16,19,21}$ but the means for such a reward structure in South Africa resides with the DoH and not with the academic instituion that wants the research conducted. Although the issues raised by respondents in our study appear in many ways to be common to the problem of research in dental schools globally, in our case the issue is complicated by the presence of two organizations, each of which has a defined goal and required outcomes. It is interesting that, in our study, the respondents directed criticism to the two organizations equally, at all levels, whether clinical or academic, for the perceived ills of the South African dental research environment.

This study was not intended to explore the advantages or disadvantages of the joint appointment model. Both partners in the joint system do an excellent job in their own right. South African health care workers are eagerly recruited by global agencies, ${ }^{24} \mathrm{a}$ testimony to the high academic standards maintained by our universities, and the DoH has accomplished a remarkable turnaround in bringing health care within reach of our entire population. ${ }^{25}$ Our intent is rather to highlight the challenge of academic staff members being tugged in two directions by masters with contradictory demands. As a result of the conflict, research has been sacrificed, and the country faces a thirty-year vacuum of research skills, research ethos, and research capacity. Changing the status quo will be long and arduous and will require commitment from all parties if national goals for research output and $\mathrm{Ph} . \mathrm{D}$. numbers are to be achieved.

Interestingly, this study has taken place at a time when others are considering academic-service partnerships in the form of patient care delivery centers as a means of solving workforce problems, promoting efficiency, ensuring cost control, and maintaining patient satisfaction. ${ }^{26,27}$ Among the many benefits identified within such systems, it appears that little thought has been devoted to the place of research training. Our experience cautions against such an initiative unless research activities are protected and agreed to by all partners. This conclusion resonates with much contained in a recent editorial on the research agenda regarding global oral health inequalities..$^{28}$

In summary, this is the first study to examine the research experiences and attitudes of academic dentists in a joint academic-service partnership. As such, it attempted to identify potential blind spots in the system that undermine its value as a research training facility as opposed to a clinical training facility. Also, this study helped to document the results of the slow, relentless erosion of research capacity over thirty years that has culminated in the situation in which South African dental research finds itself today. In doing so, we hope our study adds to the ongoing debate about knowledge creation and Ph.D. production in South Africa as well as globally.

While we have explored the surface effects of our academic-service partnership on dental research outputs, we have been unable to come to grips with the deeper complexities that bedrock our situation. Doing so will require intensive and frank debate among leading stakeholders to provide pointers to the way forward.

\section{REFERENCES}

1. Vaughn CL. Alternatives to the publication subsidy for research funding. S Afr J Sci 2008;104:91-6.

2. Blankley WO, Booysens I. Building a knowledge economy in South Africa. S Afr J Sci 2010;106:11-2.

3. Academy of Science of South Africa. Report on a strategic approach to research publishing in South Africa. Pretoria: Academy of Science of South Africa, 2006.

4. Grossman ES, Mogotsi M, Cleaton-Jones PE. The MRC/ Wits Dental Research Institute: its publication record 1954-2004. S Afr J Sci 2006;102:371-4.

5. Grossman ES. DRI productivity and participation at the SA IADR (1967-2004). SADJ 2007;62:398-404.

6. Grossman ES. Participation of dental researchers at annual SA IADR conferences (1967-2004): drivers and passengers. SADJ 2008;63:10-4.

7. Pilcher ES, Kilpatrick AO, Segars J. An assessment of promotion and tenure requirements at dental schools. J Dent Educ 2009;73(3):375-82.

8. Academy of Science of South Africa. The PhD study. Pretoria: Academy of Science of South Africa, 2010.

9. Academy of Science of South Africa. Consensus report on revitalising clinical research in South Africa. Pretoria: Academy of Science of South Africa, 2009.

10. Grossman ES, Cleaton-Jones PE. Pipelines or pipe dreams? Ph.D. production in a South African dental research institute 1954-2006. Perspect Educ 2011;29: 111-25.

11. Department of Health. White paper for the transformation of the health system in South Africa. 1997. At: www.info. gov.za/whitepapers/1997/health.html. Accessed: December 3, 2010.

12. Department of Health. Health overview, 2006. At: www. doh.gov.za/docs/reports/annual/2006/overview1.pdf. Accessed: August 5, 2012.

13. Health Professionals Council of South Africa, Subcommittee for Postgraduate Education and Training (Medical). Guideline on the minimum conditions of service, education, and training of registrars and subspecialist trainees in South Africa. Pretoria: Health Professionals Council of South Africa, 2010. 
14. Memorandum of agreement between the Gauteng Department of Health and the Universities of Limpopo Medunsa Campus, Pretoria, and the Witwatersrand. Johannesburg: Gauteng Provincial Government, 2008.

15. Baum BJ, Scott J, Bickel M, Gombos G, Greenspan JS, Guo W, et al. Global challenges in research and strategic planning. Eur J Dent Educ 2002;6(Suppl 3):179-84.

16. Brodin P, Bennett I, Appleton J, Bonta Y, Feher E, Fiehn NE. Ensuring research productivity in the future faculty. Eur J Dent Educ 2002;6(Suppl 3):97-106.

17. Murray JJ. Pressures on dental education: a personal view. Br Dent J 2002;192:433-5.

18. Townsend G, Thomas R, Skinner V, Bissell V, Cohen L, Cowpe J, et al. Leadership, governance, and management in dental education: new societal challenges. Eur J Dent Educ 2008;12(Suppl 1):131-48.

19. Trotman CA, Bennett E, Scheffler N, Tulloch JC. Faculty recruitment, retention, and success in dental academia. Am J Orthod Dentofacial Orthop 2002;122:2-8.

20. Haden NK, Hendricson W, Ranney RR, Vargas A, Cardenas L, Rose W, et al. The quality of dental faculty work-life: report on the 2007 dental school faculty work environment survey. J Dent Educ 2008;72(5):514-31.

21. Oakley M, Vieira AR. The endangered clinical teacher scholar: will this eliminate discovery from the dental school environment? J Dent Res 2008;87:200-2.
22. Rushton VE, Horner K. Academic dentistry. J Dent 2008;36:472-80.

23. Freer TJ. Contemporary issues in dental education in Australia. Aust Dent J 2010;55:20-7.

24. Dumont JC, Meyer JB. The international mobility of health professionals: an evaluation and analysis based on the case of South Africa. In: Trends in international migration: annual report. Paris: Organization for Economic Cooperation and Development, 2003:117-54.

25. Department of Health. An overview of health and health care in South Africa 1994-2010: priorities, progress, and prospects for new gains. 2010. At: www.doh.gov.za/docs/ reports/2010/overview1994-2010.pdf. Accessed: April 18, 2011.

26. Bleich MR, Hewlett PO, Miller KL, Bender K. Beyond tradition: synergizing intellectual and material capital to forge the new academic-service partnership. J Prof Nurs 2004;20:285-94.

27. Formicola AJ. Dental school clinics as patient care delivery centers: a paradigm shift in dental education. J Dent Educ 2008;72(Suppl 2):18-20.

28. Williams DM. Global oral health inequalities: the research agenda. J Dent Res 2011;90:549-51. 